\title{
Living with 'Aliens':
}

\section{Contrasting Public Perceptions and Experiences of Immigration at a 'National' and 'Local' Level}

\section{Dr Clare E Griffiths}

\section{Lecturer in Criminology, School of Sociology \& Criminology, Keele University}

Dr Clare E Griffiths explores public attitudes toward immigration and its assumed association with crime and insecurity at a national and local level, attempting to paint the existing 'gloomy' picture in a more positive light.

A recent article in The Guardian (Boffey, 2013) entitled 'immigration is British society's biggest problem, shows survey of public' details new findings that nearly a third of the British public who took part in the poll perceive immigration to be one of the greatest causes of social division. Segregation and the 'parallel lives' that diverse cultures lead have been high on the political agenda ever since the 2001 Northern riots in the towns of Oldham, Bradford and Burnley where various government policies have attempted to promote community cohesion and integration in diverse neighbourhoods. The topic of immigration and its imagined 'threat' to 'British' values and to 'British' communities has arisen again recently with both the Romanian and Bulgarian migration flows, and the killing of British soldier Lee Rigby; both of which have sparked a hostile response in negative media portrayals of immigrants or in protests against immigration involving the far right.

Government and media accounts of immigration often paint, either explicitly or implicitly, a rather 'gloomy' picture of immigration in the UK, with so-called 'alien' cultures being cited as sources of division, unrest, and insecurity. This has resulted in the criminalisation of both immigrants themselves and immigration more generally (Aliverti, 2012). Indeed, the customary political discourse on immigration is one of cutting numbers, curbing its flow, and protecting 'our' borders (Young, 2007).

This theme has similarly been taken up in the more classic criminological literature that variously shows a link between 'strangers', 'immigrants', 'outsiders' or 'others' with images of danger, disorder and crime in the minds of the more so-called 'established' social groups (Young, 2007). These 'outsider' groups are therefore often feared by the established majority and are conceived as 
a threat to the existing moral and social order due to their perceived association with crime, conflict and social misconduct.

However, the 2013 report by the think tank British Future called 'State of the Nation: Where is Bittersweet Britain Heading?' hints that something slightly more complex might be going on here by highlighting an important distinction in public perceptions of immigration. The report suggests that immigration is perceived as a problem nationally to a much greater extent than it is locally. Crucially this was the case irrespective of the spatial distribution of immigration itself. In other words, regardless of whether local areas are experiencing a great deal of immigration, this pattern in attitudes remains broadly the same. Similar findings were expressed in 2012 by Saggar and Somerville, who noted that approximately three quarters of the British public felt hostile towards immigration as a national problem but the majority were relatively positive about levels of integration at a more local level.

This resonates with Kumlin's (2004) helpful conceptualisation of 'sociotropic' versus 'egotropic' attitudes in relation to economic factors and voting behaviour. Sociotropic perceptions are, according to Kumlin (2004), perceptions of macroeconomic phenomena. Egotropic concerns are more related to personal experiences, such as personal financial experiences. Applying this conceptualisation here, it can be argued therefore that the public seem to hold negative 'sociotropic' perceptions of immigration and its perceived consequences for the country overall. Despite this, the general public hold rather more favourable views toward immigration in their local area. In other words, they hold more positive 'egotropic' perceptions of immigrants that live alongside them as neighbours. There hence appears to be a discrepancy between attitudes at the 'abstract' or 'sociotropic' level of social life as compared to the 'concrete' or 'egotropic' level.

Adding greater depth to these findings presented by British Future, my own research into Polish immigration and its association with crime and conflict similarly found that the majority of local established residents did indeed express a range of concerns regarding immigration as a mass social movement of people and its effects on the country as a whole, in particular the subsequent strain on resources that would ensue:

"I think that the main problem is ... that we've had a very large increase in population ... over a period of probably up to five years, less than five years ... they don't all necessarily speak English and with the children they put extra demands on schools, they put extra demands on doctors on the health facilities in the town, and I think to have such a large increase over 
such a short period of time puts a great strain on the normal structure of everyday living" [Established resident in a focus group discussion].

Despite this 'abstract' or 'sociotropic' concern of immigration, the results of the survey and focus groups showed that these residents went on to express tolerant and even favourable views toward the orderly behaviour of Polish immigrants living alongside them at the 'concrete' or 'egotropic' level. Furthermore, rather than conflict and animosity stemming from a mass inflow of immigrants in this area, the results showed a more subtle and nuanced situation where conflict encounters were minimised through small acts of politeness and minor courtesies between locals and immigrants.

I will let just three voices speak out from the 'established' and 'immigrant' communities who took part in focus group discussions:

"Even though I don't meet my English neighbours very often, things like holding the door or patiently waiting for a parking space are common and nice to experience...

“...English people are generally more approachable and open than Poles. Even strangers greet each other on the streets" [Polish immigrants in a focus group discussion].

"My Polish neighbours are quite startlingly different to what I expected, they've been very very helpful and friendly" [Established resident in a focus group discussion].

These groups generally strived to find the commonalities (rather than the differences) that existed between them and acted in a positive and civil way. Combined with the British Future survey results, this collection of findings therefore begins to paint a less 'gloomy' and more complex picture of public attitudes toward immigration and its assumed association with crime and insecurity. A process of 'othering' does indeed have the potential to take place in the 'abstract' or 'sociotropic' social world. However, diverse communities do have the potential to act in a positive and polite way towards 'others' rather than in a fearful and self-interested fashion in the 'concrete' or 'egotropic' social world. This demonstrates that people do not inevitably seek out the negatives or act in selfinterested rational ways; that often people want to be nice to each other, they want to do things that help other people rather than themselves, they want to find what they have in common with other people rather than focus solely on what is different between them.

Supporting recent findings from Saggar and Somerville's (2012) report on immigration and integration policy, this therefore reiterates that proximity and social contact between diverse groups at the 'egotropic' level of social life is crucial. Sagger and Somerville (2012: 5) argue that attitudes toward immigration, particularly at the 'sociotropic' or 'abstract' level, are 'vortex' issues that "suck 
in views on a range of other issues such as trust in politicians, ability to influence decisions affecting local communities, provision of public services, and so on." In a time of 'austerity' when the coalition government is placing cuts on welfare and other public services, as well as on community cohesion policies and emphasising more of a shift towards 'laissez-faire' and 'self-help' approaches, this 'vortex' of discontent attitudes has the potential to widen and become more exacerbated (Collett, 2011). Immigration may thus be a convenient receptacle for a whole host of wider ontological concerns. Unless policy efforts are directed towards dispelling the myths and stereotypes that exist at this 'sociotropic' or 'abstract' level and in tackling the 'vortex' of public concerns, there is perhaps greater potential of this filtering down to disrupt the rather fragile positive social interaction that is more capable of existing at the 'egotropic' or 'concrete' level of social life.

\section{References}

Aliverti, A. (2012) 'Making People Criminal: The Role of the Criminal Law in Immigration Enforcement', Theoretical Criminology, 16: 417-434.

Boffey, D. (2013) 'Immigration is British society's biggest problem, shows survey of public'. The Guardian, $13^{\text {th }}$ January 2013.

British Future (2013) 'State of the Nation: Where is Bittersweet Britain Heading?'. Retrieved February 2013: http://www.britishfuture.org/wp-content/uploads/2013/01/State-of-the-Nation2013.pdf

Collett, E. (2011) Immigrant Integration in Europe in a Time of Austerity. Migration Policy Institute: Washington, DC.

Kumlin, S. (2004) The Personal and the Political: How Welfare State Experiences Affect Political Trust and Ideology. New York: Palgrave.

Saggar, S., and Somerville, W. (2012) Building a British Model of Integration in an Era of Immigration: Policy Lessons for Government. Migration Policy Institute: Washington, DC.

Young, J. (2007) The Vertigo of Late Modernity. London: Sage. 